\title{
Molybdena on Titania \\ I. Preparation and Characterization by Raman and Fourier Transform Infrared Spectroscopy
}

\author{
K. Y. S. Ng AND E. Gulari ${ }^{1}$ \\ Department of Chemical Engineering, The University of Michigan, Ann Arbor, Michigan 48109
}

Received February 14, 1984; revised $\Lambda$ ugust 29, 1984

\begin{abstract}
Titania-supported molybdenum and cobalt-molybdenum catalysts were prepared by the dry impregnation and equilibrium adsorption techniques. Raman and Fourier Transform Infrared spectroscopy were used to follow the changes the catalysts underwent during the drying and calcination stages. The results indicate that the nature of the surface species depends on the loading, $\mathrm{pH}$ of the starting solution, and the method of catalyst loading. It was found, for coverages calculated to be less than a monolayer, that the main surface species are tetrahedral molybdates. As the loading increases, octahedrally coordinated polymeric surface species form. Above the monolayer coverage, $\mathrm{MoO}_{3}$ is also formed. After calcination the spectra of catalysts prepared by the equilibrium adsorption technique change much less than those for catalysts prepared by the dry impregnation technique. Addition of cobalt to titania-supported molybdenum catalysts suppresses the formation of bulk $\mathrm{MoO}_{3}$ and leads to the formation of a cobalt molybdate phase. The results show that surface molybdates interact strongly with the support, $\mathrm{TiO}_{2}$. 1985 Academic Press, Inc.
\end{abstract}

\section{INTRODUCTION}

Supported Co-Mo catalysts have been the subject of extensive investigations $(I-$ 3) because of their importance in the hydrodesulfurization (HDS) process. Much of this effort has been focused on the nature of the active sites in the $\mathrm{Co}-\mathrm{Mo} / \mathrm{Al}_{2} \mathrm{O}_{3}$ system. A better understanding of their functions will provide fundamental information for fabricating more resistant catalysts for heavy residues and synthetic-derived feeds. Three different models, the monolayer model (3), the intercalation model (4$6)$, and the contact synergism model (7) have been proposed to describe the function of the sulfided catalysts. None of these can be considered to be proven at this moment. It is not the intent of this paper to discuss the various models, but to provide information that will shed some light on the Co-Mo system; in particular, the nature of

\footnotetext{
${ }^{1}$ To whom correspondence regarding this paper should be sent.
}

Co-Mo and Mo oxide on a more strongly interacting support, titania.

There have been only a few studies on the $\mathrm{Mo} / \mathrm{TiO}_{2}$ system. Tanaka et al. (8) found that molybdenum oxide supported on $\beta$-titania has a negligible effect on the hydrogen scrambling of olefin during the metathesis reaction, while for molybdenum oxide supported on alumina and zirconia, the hydrogen scrambling of olefin surpasses the metathesis. They also claimed that the $\mathrm{MoO}_{3}$ loaded on titania with $10 \mathrm{wt} \%$ or less could be reduced to nearly zero-valent molybdenum with hydrogen at $500^{\circ} \mathrm{C}$ after $1 \mathrm{~h}$. This is in contrast to $\mathrm{MoO}_{3}$ on alumina, which can hardly be reduced to below $\mathrm{Mo}^{4+}$. Okazaki et al. (9) found the activity of supported moly-oxide catalysts for the reduction of $\mathrm{NO}$ with $\mathrm{NH}_{3}$ followed the order: $\mathrm{TiO}_{2}>\mathrm{ZrO}_{2}>\mathrm{Al}_{2} \mathrm{O}_{3}>\mathrm{SiO}_{2}$. Swanson et al. (10) found that the n-hexane isomerization activity of molybdenum oxide is more substantial on supports with stronger interactions, such as titania, zcolites, and $\gamma$-alumina. 
One of the main disagreements between the models concerns the role of the support in the HDS catalysts. The interaction of Mo and Co with the support is important in the monolayer model, but plays no role in the intercalation and contact synergism models. Ahuja et al. (11) have studied the support effect of the Mo and Co sulfide catalysts and have found that $\mathrm{Al}_{2} \mathrm{O}_{3}$ and $\mathrm{Al}_{2} \mathrm{O}_{3}-\mathrm{SiO}_{2}$ are better supports than pure $\mathrm{SiO}_{2}$. They explained the differences in terms of the acid function of the carrier. Kurita et al. (12) found that catalysts supported on $\mathrm{Al}_{2} \mathrm{O}_{3}$ are much more active than on $\mathrm{Al}_{2} \mathrm{O}_{3}-\mathrm{SiO}_{2}$ under industrial $\mathrm{HDS}$ reaction conditions. Gajardo et al. (13) characterized a series of cobalt molybdenum oxide catalysts and observed that there is a much poorer dispersion of $\mathrm{Co}$ on $\mathrm{SiO}_{2}$ as compared to $\mathrm{Al}_{2} \mathrm{O}_{3}$. They concluded that the much poorer activity of $\mathrm{CoMo} / \mathrm{SiO}_{2}$ is due to poor dispersion of cobalt and molybdenum species in their sulfide forms, which is mainly determined by the dispersion of the oxide precursor forms. The extent of dispersion, on the other hand, depends on the degree of support interaction. Tops $\varnothing \mathrm{e} e t$ al. (14) also concluded from their studies that the support plays an essential role in the formation of cobalt-containing phases in oxidic and sulfided states.

Apparently, a stronger support interaction leads to better Mo oxide and Co oxide dispersion, and better Mo sulfide and Co sulfide dispersion, as well as higher activity. Of course, the picture is not that simple; the activity also depends on the type of active species actually formed.

Despite the fact that the $\mathrm{Mo} / \mathrm{TiO}_{2}$ system has shown improved catalytic activity when compared with alumina- or silica-supported molybdenum systems $(8-10)$, no detailed characterization studies on the structure of these catalysts have been performed. In this paper, we report the effect of preparation conditions: loadings of molybdenum and cobalt, mode of preparation, order of impregnation, $\mathrm{pH}$ of impregnation solutions, drying, and calcining con- ditions on the structure of the catalysts. Laser-Raman spectroscopy was used since it has been shown to be well suited for studying the changes in the catalyst structure during preparation. Infrared spectroscopy was also used to complement the Raman results.

\section{EXPERIMENTAL METHODS}

\section{IIa. Instrumentation}

IIa.1. Raman spectroscopy. Raman spectra were obtained with a Spex Triplemate spectrograph coupled to a Tracor Northern 1024 large-area intensified diode array detector. A Lexel Model No. $95 \mathrm{Ar}^{+}$ laser was used as the excitation source. A grating monochromator was used to reject any spurious lines and background from the laser before the radiation entered the spectrometer. The 488.0-nm line was the excitation source and typical power at the pellet surface was on the order of $50 \mathrm{~mW}$. Most spectra were taken with a $2-\mathrm{cm}^{-1}$ resolution; $4-\mathrm{cm}^{-1}$ resolution was used for samples that had low signal-to-noise ratios. Since the spectrum is totally digital and no gratings were moved, spectral subtraction and signal averaging were used to improve the signal-to-noise ratio. The catalyst samples were pressed into the form of pellets (typical pressure $15,000 \mathrm{psi}$ ) and rotated at $2000 \mathrm{rpm}$ in a Spex Model 1445A sample rotator to avoid local heating.

IIa.2. Infrared spectroscopy. All the ir spectra were taken with a Digilab FTS 20/C FTIR spectrometer with $2-\mathrm{cm}^{-1}$ resolution. In order to make the pellets transparent the catalysts were thoroughly mixed and diluted with $\mathrm{KBr}$. Using the digital subtraction capability of the spectrometer the support spectrum was subtracted from the sample spectra to obtain only the spectrum of Mo and Co oxides on the surface. Solution spectra were obtained by using an ATR cell and subtracting off the water spectrum.

\section{IIb. Catalyst Preparation}

Supported Mo catalysts were prepared by both the "dry impregnation" technique 
and the "equilibrium adsorption" technique. For supported Mo-Co catalysts, only the dry impregnation technique was used. Support material was P-25 titania from Degussa (surface area $50 \pm 5 \mathrm{~m}^{2} / \mathrm{g}$ ). Solutions were prepared from ammonium heptamolybdate (Fisher Scientific Co.) and cobalt nitrate salts (Fisher Scientific Co.). Water was doubly distilled. The $\mathrm{pH}$ of the solutions was adjusted by adding nitric acid or ammonium hydroxide.

The equilibrium adsorption catalysts were prepared with dilute molybdate solutions as suggested by Wang and Hall (15). Typically, $2 \mathrm{~g}$ of support were allowed to equilibrate with $250 \mathrm{~cm}^{3}$ of $0.007 M$ ammonium heptamolybdate solution for $100 \mathrm{~h}$. The catalysts were then filtered off from the excess solution. The amount of molybdenum deposited was determined by atomic absorption spectroscopy. Catalysts prepared by both techniques were then oven dried at $110^{\circ} \mathrm{C}$ for $24 \mathrm{~h}$. Final calcination was carried out in air at $500^{\circ} \mathrm{C}$ for $24 \mathrm{~h}$.

\section{RESULTS}

\section{IIIa. Raman Spectroscopy}

The strong support bands below $700 \mathrm{~cm}^{-1}$ could not be subtracted off reliably; thus only the region above $700 \mathrm{~cm}^{-1}$ was used in our final analysis. This frequency range covers the antisymmetric $\mathrm{Mo}-\mathrm{O}-\mathrm{Mo}$ and symmetric and antisymmetric Mo $=\mathrm{O}$ terminal stretches of the isopolyanions of molybdenum and oxygen reported extensively in the literature $(16-18)$.

$\mathrm{Mo} / \mathrm{TiO}_{2}$ catalysts prepared by the impregnation method. Figure 1 shows a representative number of spectra for the impregnation catalysts after drying and calcination as a function of Mo loading. One single broad band covering the region from 850 to $980 \mathrm{~cm}^{-1}$ is seen for all the samples after drying. At the lowest loading this peak is symmetric and has two components at 935 and $945 \mathrm{~cm}^{-1}$ with the former being slightly stronger. As the loading increases from 1 to $15 \%$ the peak frequency shifts to higher

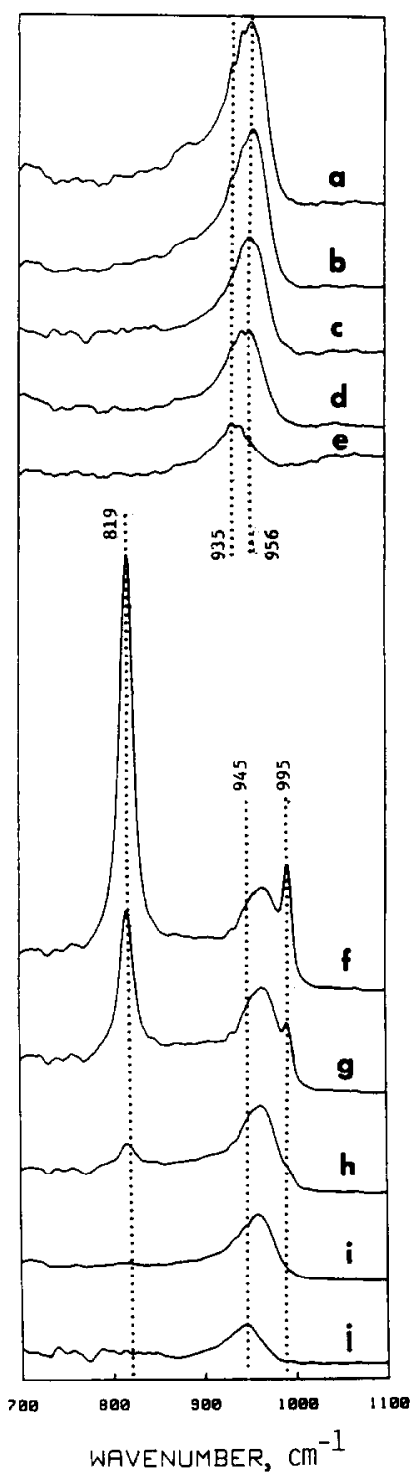

FIG. 1. Raman spectra of $\mathrm{Mo} / \mathrm{TiO}_{2}$ catalysts prepared by impregnation method as a function of Mo loading. (a-e) Are dried spectra and $(\mathrm{f}-\mathrm{j})$ are calcined spectra. Mo loadings (\%); (a, f), 15; (b, g), 10; (c, h), 5; (d, i), 3; (e, j), 1 .

wavenumbers reaching $956 \mathrm{~cm}^{-1}$, there are low-frequency side shoulders at 935 and $945 \mathrm{~cm}^{-1}$. Calcination of these samples results in shifting the peak frequency of the broad band to even higher wavenumbers, and as the monolayer coverage is exceeded (calculated to be around 4.5\%) sharp bands at 819 and $995 \mathrm{~cm}^{-1}$ indicate the formation 


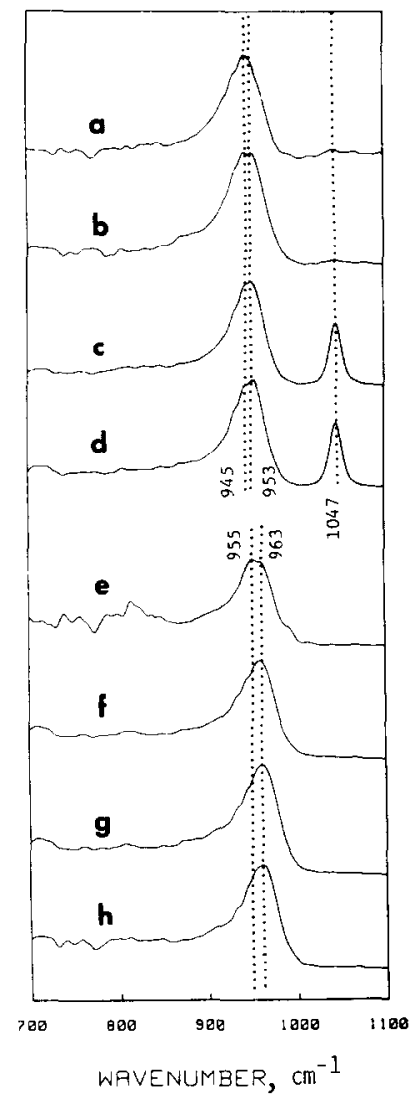

FIG. 2. Raman spectra of $3 \% \mathrm{Mo} / \mathrm{TiO}_{2}$ catalysts as a function of $\mathrm{pH}$. (a-d) Are dried spectra and (e-h) are calcined spectra. pHs of the impregnation solutions; (a, e), 9; (b, f), 5; (c, g), 2; (d, h), 1. The sharp band at $1047 \mathrm{~cm}^{-1}$ is due to the nitrate anion.

of bulk-like $\mathrm{MoO}_{3}$. The peak frequency of the broad band is $945 \mathrm{~cm}^{-1}$ for the $1 \%$ loading catalyst and increases to $964 \mathrm{~cm}^{-1}$ as the loading reaches $5 \%$ and does not change with further increases in loading. The intensity of this band also stays the same once the monolayer coverage is reached.

Figure 2 shows the effect of the impregnating solution $\mathrm{pH}$ on the Raman spectra at constant Mo loading. Here we see that $\mathrm{pH}$ has a subtle effect on the nature of the surface species. For the pH 1 sample in the dried state the broad Raman band consists of two peaks at 945 and $953 \mathrm{~cm}^{-1}$. A shoulder at $935 \mathrm{~cm}^{-1}$ is also detectable. As the $\mathrm{pH}$ increases the intensity of the $945-\mathrm{cm}^{-1}$ peak increases at the expense of the 953- $\mathrm{cm}^{-1}$ peak. Upon calcination the spectra of

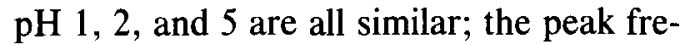
quency is $963 \mathrm{~cm}^{-1}$ with possible small shoulders on the low-frequency side. The pH 9 spectrum, however, is different in that the main peak clearly has two equal components at 955 and $963 \mathrm{~cm}^{-1}$.

Equilibrium adsorption catalysts. It has been suggested by Wang and Hall (15) that molybdena/alumina catalysts prepared by the impregnation or the incipient wetness technique are ill defined as to the state of the molybdate anion deposited on the support surface. We also prepared numerous catalysts by the equilibrium adsorption technique in order to properly study the nature of the surface molybdates. The solution concentration was kept constant at $0.007 M$. Table 1 gives the starting and ending $\mathrm{pHs}$ of the solutions used in preparing the equilibrium adsorption catalysts. We see that the changes in the $\mathrm{pH}$ are minimal almost within the error limits of the measuring process, and yet, the ending $\mathrm{pHs}$ are always higher than the starting $\mathrm{pHs}$ as one would expect. It has been shown that the rate of Mo uptake by catalyst support will level off within the first $2 \mathrm{~h}$ (15). By stirring the support and the loading solution for 100 $h$ we made sure that our samples had reached equilibrium. Figure 3 shows per-

\section{TABLE 1}

The Starting and Ending pHs of the Solutions Used in Preparing the Equilibrium Adsorption Catalysts

\begin{tabular}{ccc}
\hline $\begin{array}{c}\text { Mo loading } \\
(\%)\end{array}$ & Starting pH & Final pH \\
\hline 3.8 & 0.61 & 0.73 \\
4.1 & 1.04 & 1.08 \\
4.2 & 1.99 & 2.02 \\
3.9 & 3.05 & 3.30 \\
3.2 & 4.05 & 4.30 \\
3.0 & 5.08 & 5.13 \\
2.8 & 5.93 & 6.01 \\
2.1 & 7.04 & 7.74 \\
2.0 & 7.84 & 8.02 \\
1.8 & 8.89 & 9.10 \\
1.1 & 9.76 & 9.80 \\
\hline
\end{tabular}




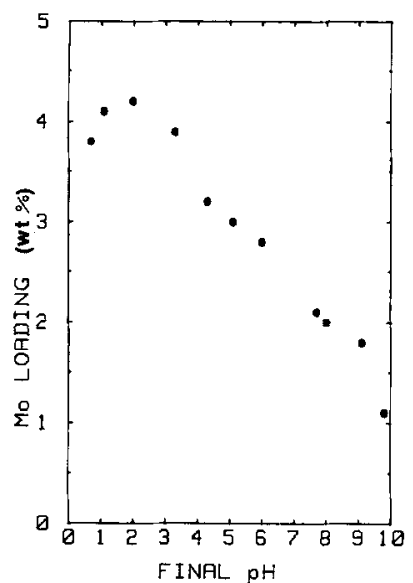

FIG. 3. Equilibrium Mo loading of $\mathrm{Mo} / \mathrm{TiO}_{2}$ as a function of $\mathrm{pH}$. The decrease in Mo loading in the very acidic range is believed to be due to the formation of positively charged Mo species.

ccntage Mo loading as a function of $\mathrm{pH}$. The shape of the curve is very similar to the one given by Wang and Hall (15) but our loadings are lower by a factor of two. Since the surface areas of their support was 57 $\mathrm{m}^{2} / \mathrm{g}$ versus our $50 \mathrm{~m}^{2} / \mathrm{g}$ we are not sure whether the difference is due to different surface hydroxyl densities or not. The decrease in loading below $\mathrm{pH} 2$ can be explained by the formation of positively charged molybdates in solution (16). In Fig. 4 the peak frequency of the broad $\mathrm{Mo}=\mathrm{O}$ stretch band is plotted as a function of the solution $\mathrm{pH}$. Compared to the samples prepared by the impregnation technique the following differences are observed: (i) below pH 5 changes in the peak frequency as a function of $\mathrm{pH}$ are almost negligible for both the dried and the calcined samples; (ii) the peak frequencies of the dried equilibrium adsorption catalysts are higher than the corresponding impregnation catalysts; (iii) for all practical purposes the peak frequencies of the calcined samples are constant from $\mathrm{pH} 0.7$ to 7.8 ; (iv) for the highly acidic samples the shift in peak frequency due to calcination is zero within error limits $\left( \pm 2 \mathrm{~cm}^{-1}\right)$; and (v) above $\mathrm{pH} 5$ for the dried samples and above $\mathrm{pH} 7.8$ for the calcined samples the peak frequency starts decreasing with $\mathrm{pH}$. We think these transitions are due to a combination of a decrease in coverage and also a change from octahedral to tetrahedral molybdate species above $\mathrm{pH} 6$.

$\mathrm{Co}-\mathrm{Mo} / \mathrm{TiO}_{2}$ catalysts. It is well known that the addition of cobalt to molybdena/ alumina catalysts can improve the hydrodesulfurization activity significantly. Such a synergetic effect is believed to have a direct relation to the catalyst structure. In order to be able to understand the structure and interaction between the cobalt and molybdenum surface oxides, samples with constant Co loading and varying Mo loading, constant Mo loading and varying Co loading, as well as samples in which the order of loading of Mo and Co varied, were prepared and studied. Figure 5 shows the spectra of $3 \%$ Co loading catalysts as a function of Mo loading. In the dried samples the $\mathrm{Co}_{3} \mathrm{O}_{4}$ phase, as determined from the intensity of the $694-\mathrm{cm}^{-1}$ peak, decreases as the Mo loading increases. The broad $\mathrm{Mo}=\mathrm{O}$ stretch band at $939 \mathrm{~cm}^{-1}$ is visible in all the spectra. As the loading increases a shoulder on the high-frequency side, indicative of polymeric species, develops. At a ratio of $10 \%$ Mo to $3 \%$ Co the $\mathrm{Co}_{3} \mathrm{O}_{4}$ peak at 694 $\mathrm{cm}^{-1}$ completely disappears. Upon calcina-

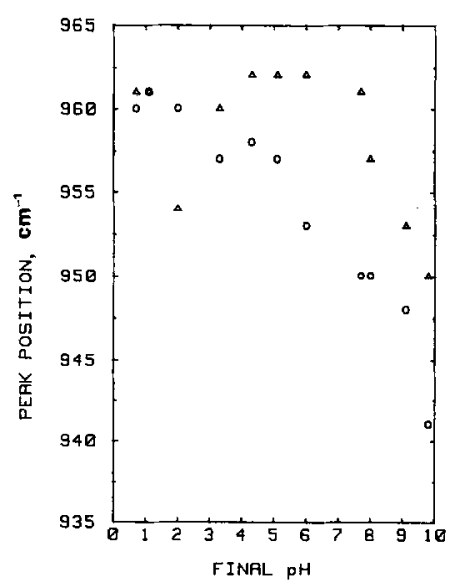

FIG. 4. Raman peak frequencies of $\mathrm{Mo} / \mathrm{TiO}_{2}$ catalysts prepared by equilibrium adsorption technique as a function of final $\mathrm{pH}$ of the excess solution. $O$, Dried spectra; $\triangle$, calcined spectra. 


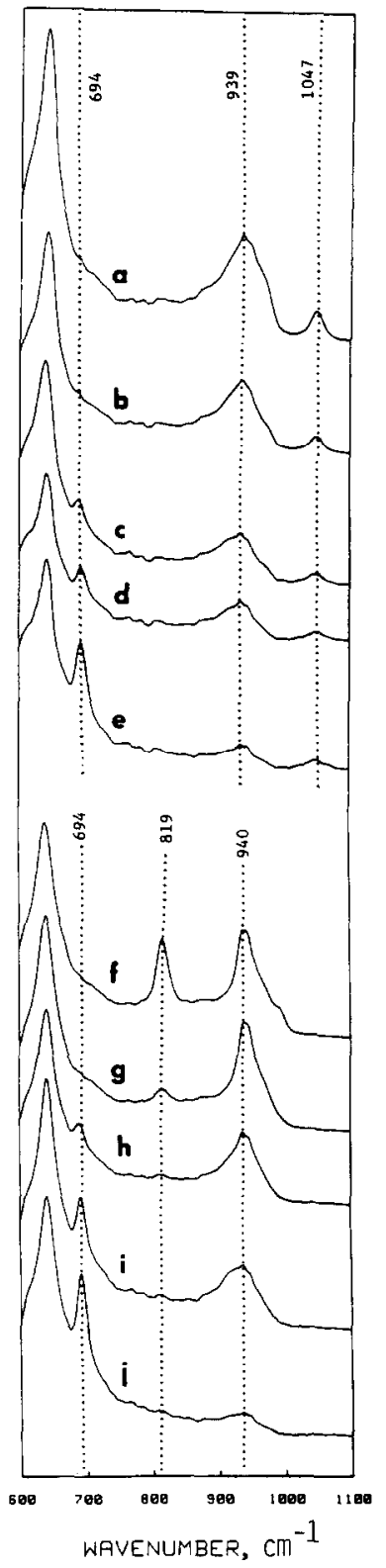

FIG. 5. Raman spectra of $\mathrm{Co}-\mathrm{Mo} / \mathrm{TiO}_{2}$ catalysts: the effect of constant amount of $\mathrm{Co}$ addition to the loading series of $\mathrm{Mo} / \mathrm{TiO}_{2}$ catalysts. (a-e) Are dried spectra and $(f-j)$ are calcined spectra. Co loading is kept constant at $3 \%$ for all catalysts. Mo loadings (\%): (a, f), 15; (b, g), 10; (c, h), 5; (d, i), 3; (e, j), 1 .

tion the signal-to-noise ratio of all the samples improves but both the 694- and 939$\mathrm{cm}^{-1}$ peaks remain in their positions. For the 10 and $15 \%$ Mo loading samples the 819 - $\mathrm{cm}^{-1}$ peak and a shoulder at $993 \mathrm{~cm}^{-1}$ appear showing the presence of bulk-like $\mathrm{MoO}_{3}$. Figure 6 shows the changes in the spectra of Co-Mo catalysts as a function of Co loading for $10 \%$ Mo loading. In the dried state, addition of cobalt drastically alters the structure of the broad $\mathrm{Mo}=\mathrm{O}$ stretch band centered around $956 \mathrm{~cm}^{-1}$. The peak frequency decreases to $939 \mathrm{~cm}^{-1}$ and the shape becomes more symmetric. For the sample containing $5 \%$ Co the presence of $\mathrm{Co}_{3} \mathrm{O}_{4}$ can also be detected from the 694$\mathrm{cm}^{-1}$ peak appearing as a small shoulder on the much stronger $\mathrm{TiO}_{2}$ peak. Again calcination improves the signal-to-noise ratio considerably. All the calcined samples

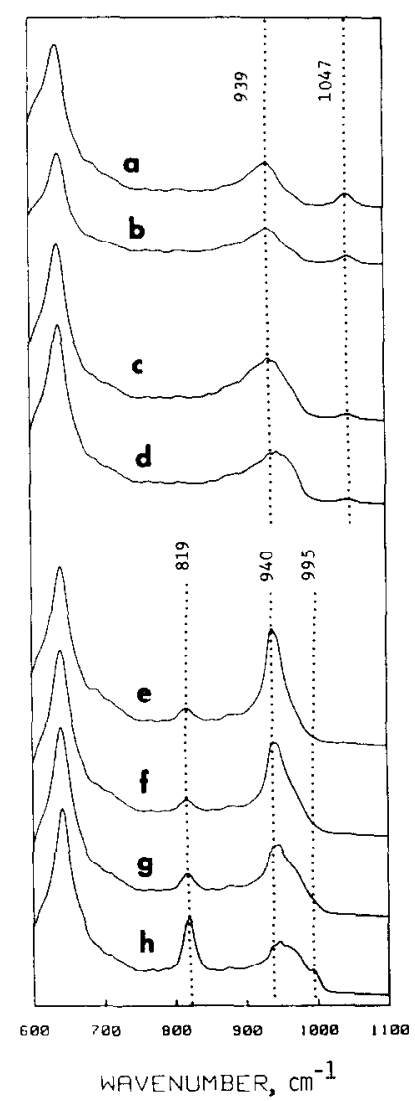

FIG. 6. Raman spectra of $\mathrm{Co}-\mathrm{Mo} / \mathrm{TiO}_{2}$ catalysts: the effect of varying amount of Co addition to a constant amount of Mo loading. (a-d) Are dried catalysts and (e-h) are calcined catalysts. Mo loading is kept constant at $10 \%$ with Co loading (\%) at $(\mathrm{a}, \mathrm{e}), 5 ;(\mathrm{b}, \mathrm{f}), 3$; (c, g), 1.5; (d, h), 0.5 . 


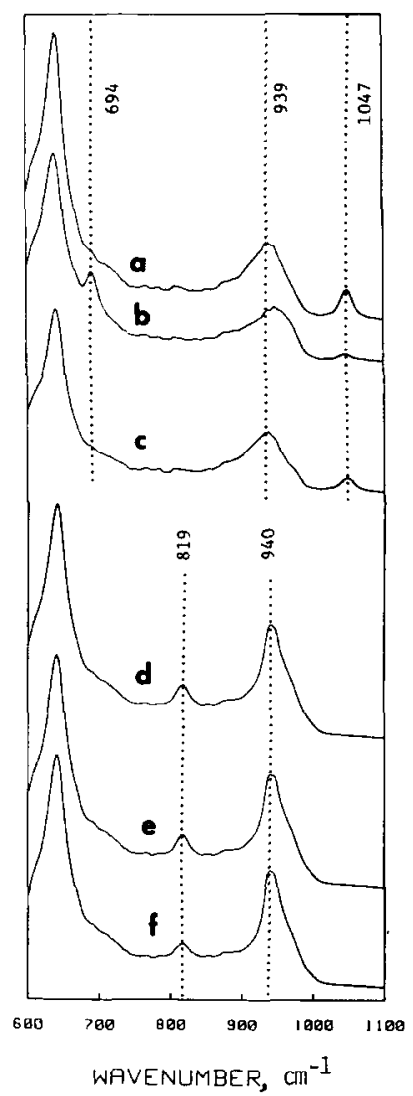

FIG. 7. Raman spectra of $\mathrm{Co}-\mathrm{Mo} / \mathrm{TiO}_{2}$ catalysts: the effect of impregnation procedures. $(a-c)$ Are dried catalysts and $(\mathrm{d}-\mathrm{f})$ are calcined catalysts. Loadings are $3 \%$ Co and $10 \%$ Mo. (a, d), Coimpregnated; (b, e), Co impregnated first; (c, f), Mo impregnated first.

show the presence of bulk-like $\mathrm{MoO}_{3}$ (819and $995-\mathrm{cm}^{-1}$ peaks). If we compare Fig. 6 with Fig. 1 we see a significant difference even for $0.5 \%$ Co loading, the amount of molybdenum trioxide has decreased considerably. Increasing the Co loading beyond $3 \%$ does not seem to affect the intensity of the $819-\mathrm{cm}^{-1}$ peak due to $\mathrm{MoO}_{3}$. Instead, we start seeing the $694-\mathrm{cm}^{-1}$ band of $\mathrm{Co}_{3} \mathrm{O}_{4}$. Figure 7 shows the Raman spectra of $\mathrm{Co}-\mathrm{Mo} / \mathrm{TiO}_{2}$ catalysts as a function of the order of addition. We see that in the dried state there is a dependence on the order of addition. If $\mathrm{Co}$ is added first it forms bulk-like $\mathrm{Co}_{3} \mathrm{O}_{4}$ and more highly aggregated surface molybdate species as judged by the higher frequency and the asymmetry of the $\mathrm{Mo}=\mathrm{O}$ stretch band. After calcination there is no difference between the three catalysts and we conclude that the order of addition is not important. In order to determine whether the $2: 1$ Mo: Co ratio is a requirement for the formation of the cobalt molybdate phase observed, and the difference in interaction between the molybdates and cobalt oxide as a function of coverage on the titania support, a series of $\mathrm{Co}-\mathrm{Mo} / \mathrm{TiO}_{2}$ samples were prepared with a fixed $\mathrm{Mo} / \mathrm{Co}$ atomic ratio of 2 to 1 . The Mo loading was varied from $3 \%$ (0.6 monolayer) to $15 \%$ (3 monolayers). Even at submonolayer coverages, an interaction between cobalt oxide and surface molybdates was observed. The $\mathrm{Mo}=\mathrm{O}$ stretch region has two resolved but overlapping peaks at 930 and $939 \mathrm{~cm}^{-1}$. The band shape is also asymmetric on the highfrequency side indicating the presence of polymeric surface molybdates. Once the monolayer coverage was exceeded there was only one peak in the $\mathrm{Mo}=\mathrm{O}$ stretch region at $939 \mathrm{~cm}^{-1}$. Increasing the total loading to $15 \%$ Mo and $4.5 \%$ Co resulted in a clean spectrum with two sharp bands at 939 and $820 \mathrm{~cm}^{-1}$, with no detectable bands at 704 or $995 \mathrm{~cm}^{-1}$.

\section{IIIb. Infrared Results}

Table 2 gives the peak frequencies of the ir bands in the dried state for $\mathrm{Mo} / \mathrm{TiO}_{2}$ samples as a function of loading. We see that the number of ir absorption bands increases as the loading increases. Sample containing $1 \%$ Mo has a single peak at $850 \mathrm{~cm}^{-1}$ in the dried state. Increasing the loading to $3 \%$ shifts the frequency of this peak to $856 \mathrm{~cm}^{-1}$ and a small shoulder at $955 \mathrm{~cm}^{-1}$ appears. The 5\% Mo sample has the main peak at $838 \mathrm{~cm}^{-1}$ and two high-frequency side shoulders at 952 and $906 \mathrm{~cm}^{-1}$, respectively. The spectra of 10 and $15 \%$ Mo loadings differ from the other two significantly in that the $906-$ and $950-\mathrm{cm}^{-1}$ peaks have the highest absorption. There are low-frequency side peaks at 860 and $810 \mathrm{~cm}^{-1}$ for the $15 \%$ Mo sample. A shoulder at $860 \mathrm{~cm}^{-1}$ 
TABLE 2

The Peak Frequencies of the ir bands in the Dried State for $\mathrm{Mo} / \mathrm{TiO}_{2}$ Samples as a Function of Loading

\begin{tabular}{|c|c|c|}
\hline \multirow{2}{*}{$\begin{array}{c}\text { Mo loading } \\
(\%)\end{array}$} & \multicolumn{2}{|c|}{ Wavenumber $\left(\mathrm{cm}^{-1}\right)$} \\
\hline & $800-900$ & $900-1000$ \\
\hline 1 & $850(s, b)$ & \\
\hline 3 & $856(s, b)$ & $955(\mathrm{~m}, \mathrm{sh})$ \\
\hline 5 & $838(s, b)$ & $\begin{array}{l}906(\mathrm{w}, \mathrm{sh}) \\
952(\mathrm{~m}, \mathrm{sh})\end{array}$ \\
\hline 10 & $\begin{array}{l}800(w) \\
860(s h)\end{array}$ & $\begin{array}{l}906(\mathrm{~s}) \\
950(\mathrm{~s})\end{array}$ \\
\hline 15 & $\begin{array}{l}810(\mathrm{~m}) \\
860(\mathrm{sh})\end{array}$ & $\begin{array}{l}906(\mathrm{~s}) \\
950(\mathrm{~s})\end{array}$ \\
\hline
\end{tabular}

Note. s, Strong; $\mathrm{m}$, medium; w, weak; $\mathrm{b}$, broad; and sh, shoulder.

and a small peak at $800 \mathrm{~cm}^{-1}$ are observed for the 10\% Mo sample. Figure 8 shows the spectra of the calcined samples as a function of loading. Again the 1\% sample has the simplest spectrum with a single large peak at $830 \mathrm{~cm}^{-1}$ and a small shoulder at $950 \mathrm{~cm}{ }^{1}$. The $3 \%$ Mo sample has a highfrequency peak at $948 \mathrm{~cm}^{-1}$ and the frequency of the main peak is at $823 \mathrm{~cm}^{-1}$ with a shoulder at $890 \mathrm{~cm}^{-1}$. Increasing the loading to $5 \%$ leads to shoulders at 995 and 885 $\mathrm{cm}^{-1}$, indicative of the presence of molybdenum trioxide. These shoulders shift the frequencies of the peaks to 950 and 826 $\mathrm{cm}^{-1}$, respectively. Further increases in loading to 10 and $15 \%$ Mo show the bulk $\mathrm{MoO}_{3}$ spectra clearly. Just as in the Raman spectra, equilibrium adsorption catalysts have cleaner ir spectra compared to impregnation catalysts. For the equilibrium adsorption samples (not shown), at $4.2 \%$ loading (complete monolayer coverage) the major peaks are at 952 and $812 \mathrm{~cm}^{-1}$ with a shoulder at $906 \mathrm{~cm}^{-1}$. The $3 \%$ loading sample spectrum is very similar to the $3 \%$ impregnation catalyst spectrum except it has a clean single peak at $956 \mathrm{~cm}^{-1}$ instead of the jagged structure seen with the impregnation sample. The main peak is at $822 \mathrm{~cm}^{-1}$ with a high-frequency shoulder at $890 \mathrm{~cm}^{-1}$. Fig- ure 9 shows the ir spectra of the two calcined $\mathrm{Co}-\mathrm{Mo} / \mathrm{TiO}_{2}$ catalysts. The $3 \%$ Co-10\% Mo sample has a broad, strong, and symmetric band at $810 \mathrm{~cm}^{-1}$ and a narrower but strong band at $958 \mathrm{~cm}^{-1}$. There is also a broad band at $1056 \mathrm{~cm}^{-1}$. In comparison, the spectrum of the $3 \% \mathrm{Co}-15 \%$ Mo is different, with strong peaks at 840 and 952 $\mathrm{cm}^{-1}$ and a shoulder at $993 \mathrm{~cm}^{-1}$, evidence for $\mathrm{MoO}_{3}$.

\section{DISCUSSION}

Before we discuss the results obtained in this investigation and compare them with those obtained using alumina support, we

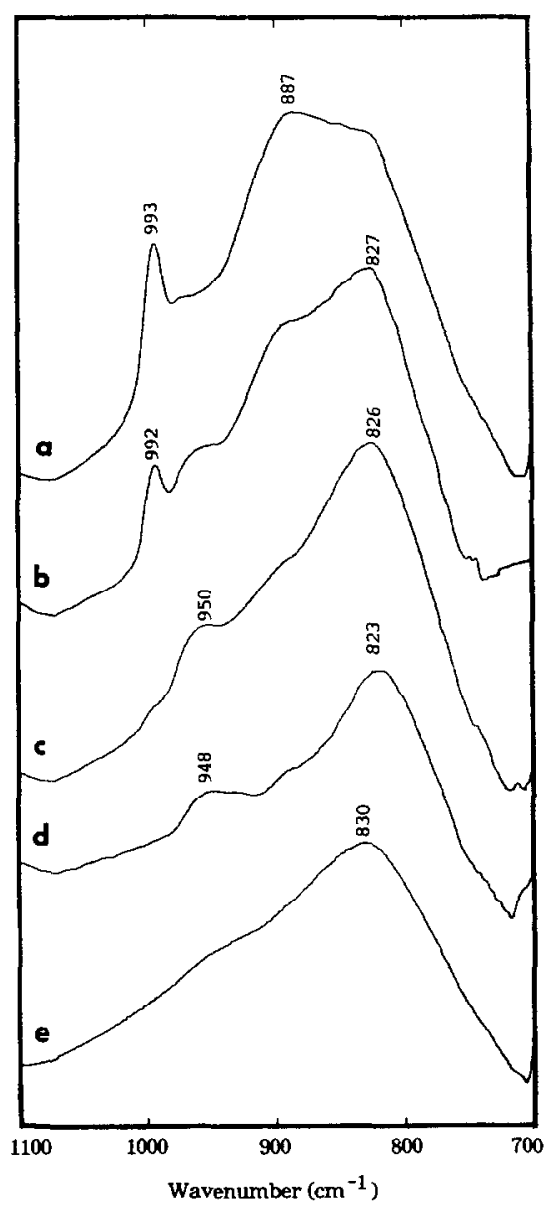

Fig. 8. Infrared spectra of calcined $\mathrm{Mo} / \mathrm{TiO}_{2}$ catalysts prepared by impregnation method as a function of loading. Mo loadings (\%): (a), 15; (b), 10; (c), 5; (d), 3 ; and (e), 1 . 


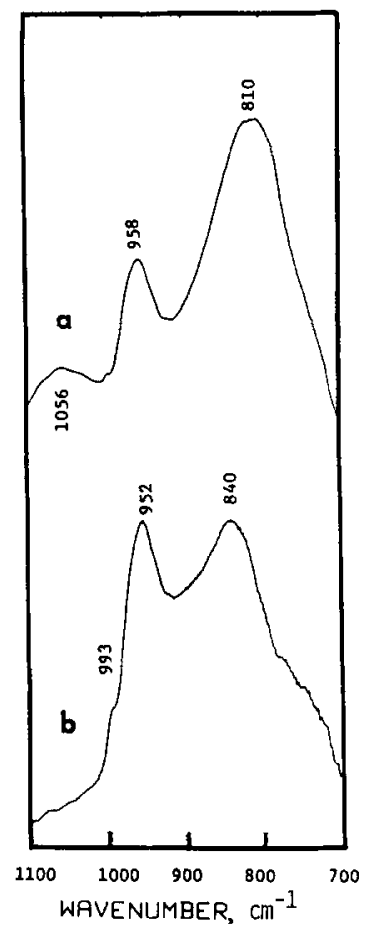

FIG. 9. Infrared spectra of calcined $\mathrm{Co}-\mathrm{Mo} / \mathrm{TiO}_{2}$ catalysts. (a) $3 \% \mathrm{Co}-10 \% \mathrm{Mo}$; (b) $3 \% \mathrm{Co}-15 \% \mathrm{Mo}$.

want to briefly emphasize the differences between titania and alumina supports. The P-25 titania support (70\% anatase, $30 \%$ rutile) used in this investigation is nonporous and has a surface area of $50 \pm 5 \mathrm{~m}^{2} / \mathrm{g}$. The preferential exposed surface is the (001) plane for anatase and (110) plane for rutile (19), and the $\mathrm{Ti}^{4+}$ ions are octahedrally coordinated for all three modifications (20). The bulk structure has six $\mathrm{O}^{2-}$ ions surrounding a $\mathrm{Ti}^{4+}$ ion and every $\mathrm{O}^{2-}$ ion has three immediate $\mathrm{Ti}^{4+}$ neighbors. On the exposed surface however, one $\mathrm{O}^{2-}$ ion is missing for every $\mathrm{Ti}^{4+}$ ion and one $\mathrm{Ti}^{4+}$ ion is missing for every $\mathrm{O}^{2-}$ ion. Because of the coordinative unsaturation of these surface ions, adsorption and subsequent dissociation of water molecules is favorable. The dissociation of water molecules creates two types of hydroxyl groups as shown in Fig. 10. The hydroxyl group that is associated with one $\mathrm{Ti}^{4+}$ site is called the terminal hydroxyl group and the other associated with two $\mathrm{Ti}^{4+}$ sites is called the bridging hydroxyl group. The resulting charge on these hydroxyls is $-\frac{1}{3}$ and $+\frac{1}{3}$, respectively. Thus terminal groups are more basic in character and are much more readily exchangeable with other anions (20). Dividing the surface area per gram by $19 \AA^{2}$, the surface area per molybdate group (21), we find that complete monolayer coverage is reached at 4.5\% Mo loading if the surface is uniformly covered. According to Boehm and Hermann (22), after degassing at $150^{\circ} \mathrm{C}$ the maximum number of surface hydroxyls on P-25 is $4.9 / 100 \AA^{2}$. If we assume that each molybdenum atom only binds to one surface hydroxyl, an assumption in agreement with Weigold's (23) model for molybdena/ alumina catalysts, we arrive at an available surface area of $20.4 \AA^{2}$ per surface molybdate group again leading to a calculated monolayer coverage at $4.2 \%$ Mo loading. Additional evidence for the one-to-one binding and uniform coverage assumptions is provided by Fig. 3 which shows that the maximum equilibrium adsorption loading achievable is $4.2 \%$ Mo at a pH of 2 . We also find that equilibrium adsorption on P-25 leads to the preparation of catalysts with monolayer and submonolayer coverages with no molybdenum trioxide formation after calcining. From these results we conclude that molybdate anions bind to the titania surface very strongly and uniformly until monolayer coverage is reached. On the titania surface, $\mathrm{Ti}^{4+}$ ions are only octahedrally coordinated and the hydroxyl groups are uniformly distributed, providing a homogeneous surface for adsorption of molybdate anions. On the other hand, on alumina $\mathrm{Al}^{3+}$ ions are octahedrally or tetrahedrally coordinated and hydroxyl groups are preferentially formed in parallel rows (24). Preferential arrangement into rows re-

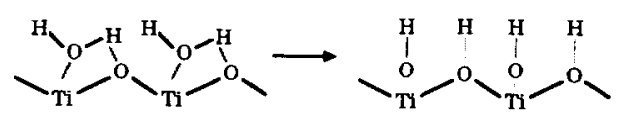

FIG. 10. The adsorption and dissociation of water molecules on the titania surface. 
TABLE 3a

Raman Peak Frequencies of Several Model Compounds

\begin{tabular}{lllll} 
& \multicolumn{3}{c}{ Wavenumber $\left(\mathrm{cm}^{-1}\right)$} \\
\cline { 2 - 5 } & $601-700$ & $701-800$ & $801-900$ & $901-1000$ \\
\hline $\mathrm{MoO}_{3}$ & $669(\mathrm{~m})$ & & $820(\mathrm{~s})$ & $996(\mathrm{~m})$ \\
$\mathrm{AHM}$ & & & $888(\mathrm{~m})$ & $937(\mathrm{~s})$ \\
$\mathrm{CoMoO}_{4}$ & & $704(\mathrm{~m})$ & & $945(\mathrm{~s})$ \\
$\mathrm{Co}_{3} \mathrm{O}_{4}$ & $694(\mathrm{~s})$ & & & \\
$\mathrm{TiO}_{2}$ & $640(\mathrm{~s})$ & & & \\
$\mathrm{MnO}_{4}^{2-}$ & & & $832(\mathrm{~m})$ & \\
$\mathrm{Mo}_{7} \mathrm{O}_{24}^{6-}$ & & & $894(\mathrm{~s})$ & \\
$\mathrm{MoO}_{8} \mathrm{O}_{26}^{4-}$ & & & $844(\mathrm{~m})$ & $945(\mathrm{~s})$ \\
& & & & $913(\mathrm{~m})$ \\
& & & & $958(\mathrm{~s})$ \\
& & & & \\
\hline
\end{tabular}

quires extensive surface diffusion and rearrangement of the molybdate anions deposited during the impregnation process and has led to significant differences between the Raman results of various investigators due to different pretreatment procedures. As a result, on titania we see molybdenum trioxide formation only after exceeding monolayer coverage whereas on alumina, molybdenum trioxide is detected even at submonolayer loadings if the impregnation method of loading is used. Sharp bulk-like $\mathrm{MoO}_{3}$ peaks at 820 and $995 \mathrm{~cm}^{-1}$ are visible in the Raman spectra of submonolayer catalysts published by Jeziorowski and Knözinger (25) and Cheng and Schrader (26). Spectra of equilibrium adsorption catalysts published by Wang and Hall (27) do not contain any of the molybdenum trioxide Raman bands. Our results, together with Wang and Hall's results, show that if one wants to avoid formation of bulk-like molybdenum trioxide and prepare only welldispersed monolayer coverage catalysts, equilibrium adsorption is the method of choice. With highly porous supports such as alumina, silica, and carbon it is possible that the redistribution of the molybdate anions is hindered during the calcining process by pore blockage which leads to the formation of $\mathrm{MoO}_{3}$ crystallites.

Perhaps the biggest difficulty facing any investigation dealing with the vibrational spectroscopy of adsorbed species is the assignment of bands. This is because of the fact that adsorption onto a support provides a distribution of chemical environments and strains. Since normal coordinate analyses of surface species is not possible the band assignments are usually made by comparison with the spectra of model compounds of known structure. However, even this approach does not yield clear-cut answers since the vibrational frequencies of the stretching modes of the terminal and bridging molybdenum oxygen groups frequently overlap (28). Tables $3 \mathrm{a}$ and b give the Raman and ir peak frequencies of the model compounds and ammonium heptamolybdate solutions that will be used in interpreting the spectra of the adsorbed molybdates.

\section{$\mathrm{Mo}_{\mathrm{TiO}}$ Samples}

Central to the past research involving molybdate-based HDS catalysts has been the question of the structure of the adsorbed species. In pure compounds and solutions of the molybdate anions the two common coordination states of the molybdates are (1) the tetrahedral $\left(T_{d}\right)$ coordination in the $\mathrm{MoO}_{4}^{2}$ tetrahedra observed in AHM solutions in the alkaline $\mathrm{pH}$ region and simple molybdates such as $\mathrm{Na}_{2} \mathrm{MoO}_{4}$ and (2) the octahedral $\left(\mathrm{O}_{\mathrm{h}}\right)$ coordination ob-

TABLE 3b

Infrared Peak Frequencies of Several Model Compounds

\begin{tabular}{|c|c|c|c|c|}
\hline & \multicolumn{4}{|c|}{ Wavenumber $\left(\mathrm{cm}^{-1}\right)$} \\
\hline & $701-800$ & $801-900$ & $901-1000$ & $1001-1100$ \\
\hline $\mathrm{MoO}_{3}$ & & $\begin{array}{l}819(\mathrm{~m}) \\
887(\mathrm{~b})\end{array}$ & $993(s)$ & \\
\hline AHM & & $\begin{array}{l}839(\mathrm{~m}) \\
877(\mathrm{sh}) \\
889(\mathrm{~s})\end{array}$ & $916(\mathrm{~m})$ & \\
\hline $\mathrm{CoMoO}_{4}$ & & & $\begin{array}{l}910(\mathrm{sh}) \\
945(\mathrm{~s})\end{array}$ & \\
\hline $\mathrm{Co}_{3} \mathrm{O}_{4}$ & 790 (b) & & & 1070 (b) \\
\hline $\mathrm{MoO}_{4}^{2-}$ & & $\begin{array}{l}833(\mathrm{~s}) \\
881(\mathrm{~s})\end{array}$ & $914(\mathrm{sh})$ & \\
\hline $\mathrm{Mo}_{7} \mathrm{O}_{24}^{6-}$ & & $\begin{array}{l}840(\mathrm{sh}) \\
883(\mathrm{~s})\end{array}$ & $930(\mathrm{sh})$ & \\
\hline $\mathrm{MoO}_{8} \mathrm{O}_{26}^{4-}$ & & $885(\mathrm{~s})$ & $\begin{array}{l}915(\mathrm{sh}) \\
943(\mathrm{~s})\end{array}$ & \\
\hline
\end{tabular}


served in AHM solutions in the $\mathrm{pH}$ range of 1 to 5 and in compounds such as AHM and $\mathrm{CoMoO}_{4}$. If we look at Table 3a we see that in solution the simple molybdate anion $\mathrm{MoO}_{4}^{2-}$ with tetrahedral coordination $\left(\mathrm{T}_{\mathrm{d}}\right)$ has Raman bands at $896\left(\nu_{1}\right)$ and $854\left(\nu_{3}\right)$ $\mathrm{cm}^{-1}$. The heptamolybdate anion $\mathrm{Mo}_{7} \mathrm{O}_{24}^{6-}$, on the other hand, has octahedral coordination $\left(\mathrm{O}_{\mathrm{h}}\right)$ in solution and has strong Raman bands at $939\left(\nu_{1}\right)$ and $896\left(\nu_{3}\right) \mathrm{cm}^{-1}$. In sharp contrast to the solution spectra we do not see any Raman bands at $896 \mathrm{~cm}^{-1}$ (characteristic of $T_{d}$ symmetry) in the spectra of any of the catalyst samples given in Figs. 1, 2 , and 4. Instead, all the spectra have the broad $\mathrm{Mo}=\mathrm{O}$ stretch band with a peak frequency that varies from 939 to $965 \mathrm{~cm}^{-1}$. Based on a similar observation on alumina support some investigators have concluded that on alumina all the molybdenum exists in octahedral coordination (29). Iannibello et al. (30) suggested that $950 \mathrm{~cm}^{-1}$ correspond to the $\mathrm{Mo}=\mathrm{O}$ frequency of a tetrahedral molybdate group bonded to the support surface. This assignment is also supported by Wang and Hall (31). Cheng and Schrader (26) also did not observe the $894-\mathrm{cm}^{-1}$ band of the tetrahedral molybdate. They explained the absence of the monomeric molybdate species by arguing that during the drying process monomeric molybdates aggregated to the polymolybdates because of the equilibrium shift. The preparation conditions $(\mathrm{pH}>6)$ of our equilibrium adsorption catalysts should favor the deposition of tetrahedral molybdates, and yet we do not observe any $890-\mathrm{cm}^{-1}$ band even in the dried state. This may be attributed to the strong binding of the molybdate anion to the terminal hydroxyls on the surface and consequent increase in bond order and $\nu_{1}$ frequency of the tetrahedral molybdate group. The Raman spectra of cquilibrium adsorption catalysts prepared with acidic solutions provide another piece of evidence for the reactivity of surface hydroxyls of titania. The frequency shifts in the Raman spcctra arc very small, indicating that reaction of the molybdate anion with the sur- face is complete during the adsorption and drying process.

In the absence of any other information it is clear that Raman spectroscopy alone cannot prove or disprove the existence of tetrahedral molybdates. If we look at the ir bands of the model compounds given in Table $3 b$ we see that the tetrahedral species have a strong ir band at $833 \mathrm{~cm}^{-1}$ and the octahedral molybdates have strong ir bands at 883 and $940 \mathrm{~cm}^{-1}$. The ir bands of the octahedral species have been assigned to continuous $\mathrm{Mo}-\mathrm{O}$ and independent or terminal Mo-O bonds, respectively (32). From the ir spectra given in Fig. 8 we see that in the $1 \%$ Mo spectrum, the major peak is at $830 \mathrm{~cm}^{-1}$. Since among our model compounds only the tetrahedral species has a strong ir band in this region we conclude that at low loadings significant amounts of tetrahedral molybdates exist on the support surface even after calcining. The presence of a shoulder at $950 \mathrm{~cm}^{-1}$ even for the $1 \%$ ( 0.25 monolayer coverage) sample indicates the formation of small amounts of polymeric species. Increasing the loading leads to the appearance of a band at approximately $950 \mathrm{~cm}^{-1}$ (terminal $\mathrm{Mo}=\mathrm{O}$ stretch) and increased absorption at $885-900 \mathrm{~cm}^{-1}$ (Mo-O-Mo-O type continuous oxygen molybdenum band stretch observed only in polymeric molybdates and molybdenum trioxide). For loadings of $10 \%$ or above this band is the dominant feature of the ir spectrum. One difficulty in interpreting the ir spectrum is the presence of the strong band at $826 \mathrm{~cm}^{-1}$ even at $5 \%$ loading. Since at this loading we have already exceeded the monolayer coverage, existence of this band cannot be attributed to tetrahedral molybdates. A medium-strength ir band at 813 $\mathrm{cm}^{-1}$ has been assigned to a different type of continuous Mo-O bond (33), and as a result, we can explain the presence of the low-frequency main peak observed even in the spectra of low $\mathrm{pH}$ equilibrium adsorption samples as being due to the overlap of the strong 885 - and $813-\mathrm{cm}^{-1}$ bands. It has also been pointed out by Cord et al. (34) 
that the distortion of the octahedral symmetry is such that nearly perfect tetrahedral coordination results and hence the strong low-frequency band at the same frequency as the $\nu_{3}$ frequency of the tetrahedral molybdates. Interestingly enough, exactly the opposite argument has been made for the case of tetrahedral molybdates adsorbed on alumina by Cheng (35). At loadings above a monolayer the ir spectra also shows the distinctive bands of $\mathrm{MoO}_{3}$ at 993 and $885 \mathrm{~cm}^{-1}$. Comparison of the calcined spectra shown in Fig. 8 with the dried spectra given in Table 2 for 1 and $3 \%$ Mo samples reveals that upon calcining the frequency of the major peak decreases by about $20-30 \mathrm{~cm}^{-1}$. This large shift indicates that there is strong interaction with the support surface during calcining. The higher-frequency bands on the other hand exhibit smaller shifts to higher wavenumbers, indicative of increased polymerization. The spectrum of the above monolayer samples in the dried state are very similar to the spectra of the octamolybdate anion in solution.

In summary, our ir and Raman results together indicate that at low coverages the majority of the surface molybdates are in tetrahedral coordination. As the coverage approaches one monolayer extensive polymerization occurs and octahedrally coordinated polymeric surface species are formed. Loading beyond a monolayer results in a monolayer of polymeric surface species and bulk-like molybdenum trioxide on top of the monolayer. In terms of assigning the Raman bands our results show that the terminal $\mathrm{Mo}=\mathrm{O}$ stretch band of the tetrahedral species is at $955 \mathrm{~cm}^{-1}$ or slightly lower; peak frequencies above $955 \mathrm{~cm}^{-1}$ are due to the octahedrally coordinated polymeric species. Figure 4 provides additional supporting evidence for this assignment; the peak frequency of all the equilibrium adsorption catalysts prepared with a solution $\mathrm{pH}$ of 8 or below are constant at $963 \pm$ $2 \mathrm{~cm}^{-1}$ after calcining; increasing the $\mathrm{pH}$ sharply decreases the peak frequency all the way down to $952 \pm 2 \mathrm{~cm}^{-1}$. The peak frequencies shown for the same catalysts in the dried state show a sharp change at a $\mathrm{pH}$ of 5.5, precisely the frequency at which the solution equilibrium between the octahedral and tetrahedral molybdates shifts. For impregnation catalysts, the effect of solution $\mathrm{pH}$ is not as visible as for the equilibrium adsorption catalysts because of the high buffer capacity of the titania surface. Nevertheless, high $\mathrm{pH}$ preparation definitely has a larger amount of tetrahedral species as compared to low $\mathrm{pH}$ preparations.

\section{$\mathrm{Co}-\mathrm{Mo} / \mathrm{TiO}_{2}$ Catalysts}

Since the majority of the industrial catalysts are cobalt promoted it is important to understand what interactions take place between cobalt and molybdenum in the oxidic state. On alumina it has been observed by previous investigators (26) that addition of cobalt suppresses the formation of bulk-like molybdenum trioxide. Our results given in Fig. 5 show that similar phenomena take place on titania support. Addition of cobalt delays the appearance of $\mathrm{MoO}_{3}$ bands until $10 \%$ Mo loading is reached and even in the spectrum of the $15 \%$ Mo loading sample the trioxide bands have much lower intensity compared to Fig. 1. The broad $\mathrm{Mo}=\mathrm{O}$ stretch peak around $950 \mathrm{~cm}^{-1}$ is also changed significantly. It is narrower and more symmetric when compared to Fig. 1. If we compare our spectra given in Figs. 5 and 6 with those of Cheng and Schrader (26) we find that in their spectra the 694$\mathrm{cm}^{-1}$ peak of bulk-like $\mathrm{Co}_{3} \mathrm{O}_{4}$ disappears at an atomic ratio of $1.67 \mathrm{Mo}$ to $1 \mathrm{Co}$. In our case the same thing happens at an atomic ratio of 2 to 1 ( $10 \%$ Mo and $3 \% \mathrm{Co} \mathrm{wt/wt).} \mathrm{It}$ is difficult to justify the existence of bulklike cobalt molybdate from the Raman spectra. Pure cobalt molybdate has a sharp and very strong Raman band at $945 \mathrm{~cm}^{-1}$, a sharp band at $704 \mathrm{~cm}^{-1}$, and a broad band at around $880 \mathrm{~cm}^{-1}$. In none of our samples did we observe the $704-\mathrm{cm}^{-1}$ band, only the broad band around $940 \mathrm{~cm}^{-1}$ is observable. Since this band is in the $\mathrm{Mo}=\mathrm{O}$ stretch re- 
gion it cannot be used as direct evidence for the presence of a cobalt molybdate phase. There is some disagreement with regards to the 704- $\mathrm{cm}^{-1}$ band for pure cobalt molybdate, Cheng and Schrader (26) did not observe it but it is clearly present in the spectra given by Medema et al. (29). This discrepancy may be due to different modifications of cobalt molybdate used. In our investigations we found that the intensity and the width of the $704-\mathrm{cm}^{-1}$ band was a function of the pressure used in making the pellets and as a result its absence does not guarantee the absence of cobalt molybdate.

Infrared spectra of $3 \% \mathrm{Co}-10 \% \mathrm{Mo}$ and 3\% Co-15\% Mo shown in Fig. 9 also do not give clues with regard to the presence of a cobalt molybdate phase. The spectrum of the $3 \%$ Co-10\% Mo sample has three strong and relatively broad bands in the region 700 to $1100 \mathrm{~cm}^{-1}$. The band at 1056 $\mathrm{cm}^{-1}$ is clearly due to cobalt oxide even though its frequency is shifted down from $1070 \mathrm{~cm}^{-1}$ for the pure $\mathrm{Co}_{3} \mathrm{O}_{4}$. The 958$\mathrm{cm}^{-1}$ peak can be due to $\mathrm{Mo}=\mathrm{O}$ stretches of adsorbed polymeric species or $\mathrm{Mo}=\mathrm{O}$ stretch of the surface cobalt molybdate even though the pure compound peak is at $945 \mathrm{~cm}^{-1}$ and as such does not provide us with any new evidence. On the high-frequency side of this band the $993-\mathrm{cm}^{-1}$ peak of the molybdenum trioxide is barely visible, indicating the presence of small amounts of bulk-like molybdenum trioxide. The very large $810-\mathrm{cm}^{-1}$ peak is intermediate in frequency between the strong 790$\mathrm{cm}^{-1}$ band of the cobalt oxide and the continuous Mo-O band at $813 \mathrm{~cm}^{-1}$. Increasing the molybdenum loading to $15 \%$ causes the $1056-\mathrm{cm}^{-1}$ peak to disappear completely and shifts the frequencies of the other two peaks to 840 and $952 \mathrm{~cm}^{-1}$. The shoulder at $993 \mathrm{~cm}^{-1}$ is also significantly higher. The shifts in the peak frequencies can be explained easily if we note that molybdenum trioxide has a very broad and strong band at $887 \mathrm{~cm}^{-1}$, right in the middle of the 958 - and $810-\mathrm{cm}^{-1}$ bands, causing the large shifts. While the ir spectra shown in Fig. 9 does not prove or disprove the existence of bulklike cobalt molybdate phase it certainly shows that a strong interaction is taking place between the adsorbed cobalt and molybdenum oxides. This finding is in agreement with the findings of the previous investigators $(26,35)$. Our results differ from the past investigators on alumina in one important aspect: Cheng and Schrader (26) found that with alumina support the order of loading was important; addition of cobalt first led to the formation of highly aggregated molybdenum species (trioxide) after calcining. As can be seen in Fig. 7 for our catalysts there is a difference only in the dried state. If $\mathrm{Co}$ is added first it forms bulk-like $\mathrm{Co}_{3} \mathrm{O}_{4}$ and more highly aggregated surface molybdates. The $\mathrm{Mo}=\mathrm{O}$ stretch peak shifts to higher frequencies and is asymmetric on the high-frequency side. After calcination there is no difference between the three catalysts and we conclude that the order of addition is not important. These results can be explained if on titania molybdenum binds to the support surface strongly. During drying and calcination the interaction of molybdates with the surface hydroxyls and with cobalt oxide are occurring simultaneously. Addition of cobalt first leads to the formation of a layer of cobalt oxide on the support surface after drying; addition of molybdenum results in the formation of polymeric molybdates on top of the cobalt oxide and on patches of surface not covered by cobalt oxide. The temperature during the drying process $\left(110^{\circ} \mathrm{C}\right)$ is not high enough to cause significant diffusion and rearrangement of the surface species. However, the calcination temperature $\left(500^{\circ} \mathrm{C}\right)$ is high enough for the molybdates anions to penetrate the thin cobalt oxide layer and interact with the surface hydroxyls of titania. This interaction leads to the formation of a strongly bound polymeric molybdate monolayer on the support surface. In order to compare with the supported samples two unsupported samples with the same $\mathrm{Mo} / \mathrm{Co}$ ratio (2/1) were prepared by physical and solution mixing and 
calcining. Both samples had identical spectra: a sum of pure cobalt molybdate and molybdenum trioxide individual spectra, significantly different than the spectrum of the supported samples, the main difference being the suppression of the $\mathrm{MoO}_{3}$ peaks for the supported samples. One plausible model in agreement with our findings is a monolayer of surface polymolybdates strongly bound to the support. In this monolayer each molybdenum atom has a single oxygen bridge to a surface titanium atom. At or below monolayer coverages addition of cobalt oxide results in a surface cobalt molybdate species in which molybdenum atoms are still bound to the support surface with oxygen bridges. At Mo loadings in excess of a monolayer, layers of cobalt molybdate (1 to 1 ratio) are formed on top of the surface monolayer of polymolybdates. We should note that even at $15 \%$ Mo and $4.5 \% \mathrm{Co}$, after subtracting $4.5 \%$ Mo for the first monolayer on the support, the atomic ratio of Mo to Co is only 1.37; thus there is little excess molybdenum left to form bulk-like molybdenum trioxide, in agreement with the small $820-\mathrm{cm}^{-1}$ peak observed in the Raman spectrum.

\section{CONCLUSIONS}

According to the results of this study we find that there are similarities and significant differences between the titania- and alumina-supported molybdena and cobaltmolybdena systems. On titania at submonolayer coverages significant amounts of tetrahedral molybdate species coexist with octahedrally coordinated polymeric molybdates. As the surface coverage increases polymeric molybdates increase at the expense of tetrahedral molybdates. Any amount in excess of a monolayer is converted to bulk-like molybdenum trioxide. One of the important differences compared to the alumina system is the fact that as long as the loading is below a monolayer no molybdenum trioxide is formed on titania even with the impregnation method of load- ing. Our results also indicate that due to the strong interaction with the surface the $\nu_{1}$ frequency of the tetrahedrally coordinated molybdates shifts to about 935-950 from $895 \mathrm{~cm}^{-1}$ observed for the anion in solution. This significant shift makes it all but impossible to use Raman spectroscopy to determine the amount of tetrahedral and octahedral surface species. All of the results obtained for the molybdena-titania system can be explained with a simple model in which each molybdenum atom shares one oxygen atom with a surface titania atom at monolayer coverage. At submonolayer coverages it is possible that each molybdenum can bind to more than one surface oxygen. In the case of $\mathrm{Co}-\mathrm{Mo} / \mathrm{TiO}_{2}$ catalysts we find that, unlike alumina-supported catalysts, the order of addition does not matter after calcining. Cobalt does not interact with the support strongly to form a stable surface or subsurface compound. Addition of cobalt suppresses the formation of bulklike molybdenum trioxide and leads to the formation of cobalt molybdate species on top of a monolayer. Our investigations using molybdena/titania catalysts are continuing, our HDS activity studies indicate that differences in structure lead to differences in activity when compared to alumina-supported catalysts, and our pyridine adsorption study shows the relationship between the structure, surface acidity, and HDS activity. These results will be published in the near future.

\section{ACKNOWLEDGMENTS}

Financial support of this research by the Dreyfus Foundation, NSF:CPE-8107724 and DMR-8100130, and by the ACS-PRF is gratefully acknowledged.

Note added in proof. After this work was completed, Stencel et al. (J. Catal. 90, 314 (1984)) have shown that prolonged exposure to water vapor in air can change the Raman spectra of alumina-supported molybdenum oxide significantly. All of our measurements were taken within several hours after calcination, but we plan to investigate the effect of water vapor on $\mathrm{Mo} / \mathrm{TiO}_{2}$ spectra in the near future. 


\section{REFERENCES}

1. Schuit, G. C. A., and Gates, B. C., AIChE J. 19, 417 (1973).

2. Grange, P., Catal. Rev. Sci. Eng. 21, 135 (1980).

3. Massoth, F. E., "Advances in Catalysis," Vol. 27, p. 265. Academic Press, New York, 1978.

4. Voorhoeve, R. J. H., and Stuiver, J. C. M., J. Catal. 23, 228 (1971).

5. Voorhoeve, R. J. H., J. Catal. 23, 236 (1971).

6. Voorhoeve, R. J. H., and Stuiver, J. C. M., J. Catal. 23, 236 (1971).

7. Delmon, B., Amer. Chem. Soc. Div. Pet. Chem. Prepr. 22(2), 503 (1977).

8. Tanaka, K., Miyahara, K., and Tanaka, K., Bull. Chem. Soc. Jpn. 54, 3106 (1981).

9. Okazaki, S., Kumasaka, M., Yoshida, J., and Kosaka, K., Ind. Eng. Chem. Prod. Res. Dev. 20, 301 (1981).

10. Swanson, W. W., Streusand, B. J., and Tsigdinos, G. A., "Proceedings, of the Chemistry and Use of Molybdenum." Climax Molybdenum Company, Ann Arbor, Michigan, 1982.

11. Ahuja, S. P., Derrien, M. L., and LePage, J. F., Ind. Eng. Chem. Prod. Res. Dev. 9, 272 (1970).

12. Kurita, S., Watanabe, T., and Takayama, N., Kogyo Kagaku Zasshi 74, 2264 (1971).

13. Gajardo, P., Pirotte, D., Grange, P., and Delmon, B., J. Phys. Chem. 83, 1780 (1979).

14. Topsøe, H., Clausen, B. S., Burriesci, N., Candia, R., and Mørup, in "Preparation of Catalysts II" (B. Delmon, P. A. Jacobs, and G. Poncelet, Eds.), p. 479. Elsevier, Amsterdam, 1979.

15. Wang, L., and Hall, W. K., J. Catal. 77, 232 (1982).

16. Ng, K. Y. S., and Gulari, E., Polyhedron 3(8), 1001 (1984).

17. Griffith, W. P., and Lesniak, P. J. B., J. Chem. Soc. A, 1066 (1969).

18. Mattes, F., Bierbusse, H., and Fuchs, J., $Z$. Anorg. Allg. Chem. 385, 230 (1971).

19. Parfitt, G. D., in "Progress in Surface and Membrane Science" (D. A. Cadenhead and J. F. Da- nielli, Eds.), Vol. 11, p. 181. Academic Press, New York, 1976.

20. Boehm, H. P., "Advances in Catalysis," Vol. 16, p. 179. Academic Press, New York, 1966.

21. Fransen, T., Van Berge, P. C., and Mars, P., in "Preparation of Catalysts" (B. Delmon, P. A. Jacobs, and G. Poncelet, Eds.), p. 405. Elsevier, Amsterdam, 1976.

22. Boehm, H. P., and Hermann, M., Z. Anorg. Allg. Chem. 352, 156 (1967); 368, 73 (1969); FlaigBaumann, R., Hermann, M., and Boehm, H. P., Z. Anorg. Allg. Chem. 372, 296 (1969); Hermann, M., Kaluza, U., and Boehm, H. P., Z. Anorg. Allg. Chem. 372, 308 (1970).

23. Weigold, H., J. Catal. 83, 85 (1983).

24. Knözinger. H., and Ratnasamy, P.. Catal. Rev. Sci. Eng. 17, 31 (1978).

25. Jeziorowski, H., and Knözinger, H., J. Phys. Chem. 83, 1166 (1979)

26. Cheng, C. P., and Schrader, G. L., J. Catal. 60, 276 (1979).

27. Wang, L., and Hall, W. K., J. Catal. 83, 242 (1983).

28. Cotton, F. A., and Wing, R. M., Inorg. Chem. 4, 867 (1965).

29. Medema, J., van Stam, C., de Beer, V. H. J., Konings, A. J. A., and Koningsberger, D., J. $\mathrm{Ca}$ tal. 53, 386 (1978).

30. Iannibello, A., Marengo, S., Trifiro, F., and Villa, P. L., in "Preparation of Catalysts, II" (B. Delmon, P. A. Jacobs, and G. Poncelet, Eds.), p. 65. Elsevier, Amsterdam, 1979.

31. Wang, L., and Hall, W. K., J. Catal. 66, 251 (1980).

32. Barraclough, C. G., Lewis, L., and Nyholm, R. S., J. Chem. Soc., 3552 (1959).

33. Clark, G. M., and Doyle, W. P., Spectrochim. Acta 22, 1441 (1965).

34. Cord, A. P., Courtine, P., and Pannetirer, G., Spectrochim. Acta Part A 28, 1601 (1972).

35. Cheng, C. P., Ph. D. thesis, University of Delaware, Newark, Delaware, 1981. 